\title{
Ante el Monumento Nacional
}

Joaquín García Monge

Escritor. Costa Rica

\section{PALABRAS CLAVE: \\ discurso, argumentación, prag- matismo, filosofía analítica, lógica formal, lógica informal, actos de habla. \\ KEY WORDS: \\ speech, argument, pragma- tism, analytic philosophy, formal logic, informal logic, speech acts.}

Gyarcia llonge

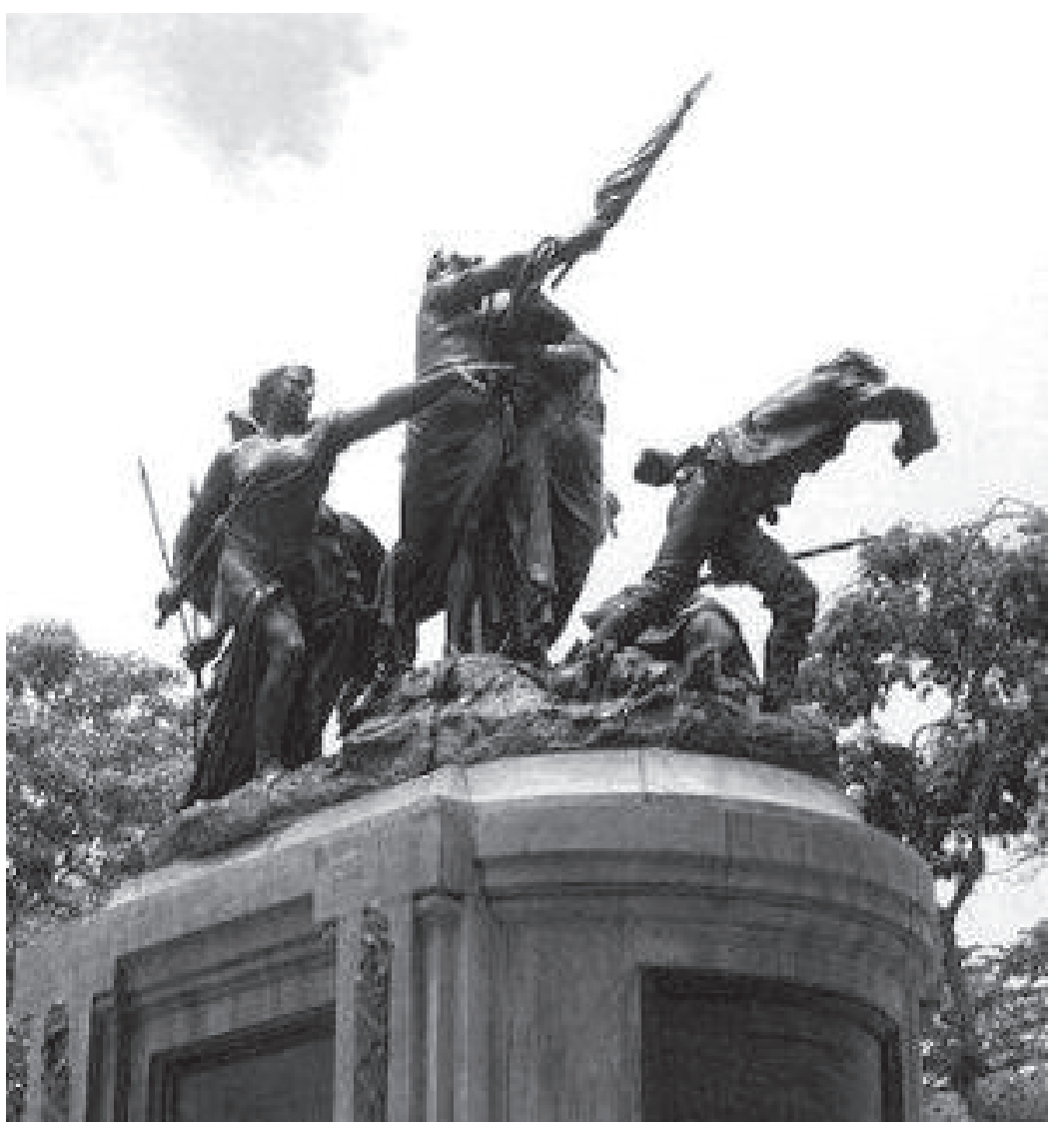

Monumento Nacional Costa Rica

Develizado el 15 de setiembre de 1895 
[Exhortación hecha a los estudiantes del Liceo de Costa Rica y del Colegio de Señoritas, en la mañana del 15 de septiembre de 1921].

Jóvenes estudiantes:

Como un testimonio de la gratitud nacional, erigióse un día este Monumento a los inmortales que en los gloriosos del 56 estuvieron resueltos a no consentir opresiones extrañas en tierras de Centro América, a vivir y a hablar por su cuenta y riesgo, en su propio nombre, de conformidad con las altas normas y el ejemplo de los augustos fundadores de estas patrias. ${ }^{1}$ Lo erigieron los mayores para perpetuar en el bronce las ínclitas hazañas de los elegidos y con ello inscribir excelsamente la perdurable lección que sirviera de ejemplo y estímulo a las futuras generaciones. Que los pueblos previsores y magnánimos recurren a los mármoles y a los bronces para simbolizar en ellos fechas memorables, y así ponerlas a salvo de olvidos o injusticias, o como columnas miliares a lo largo de la vida, para recordarles a los que vienen que no son hijos de las peñas, que tienen precursores admirables e ilustres y una tradición estimable que conocer, respetar y proseguir.

A estos monumentos se concurre en horas solemnes como la presente, a renovar la fe en los destinos de la Patria, a buscar inspiración y luces, enseñanzas y estímulos para continuar la ruta emprendida, en alto la cabeza y regocijado el corazón.

Lo erigieron los mayores para enseñarnos cómo se defiende con fiereza el suelo nativo, que da el sustento y la libertad; cómo es bueno morir, y se sabe morir sin cobardías, por causas dignas, cuando la injusticia y la opresión amenazan el decoro de la Patria; cómo pelean con audacia los pueblos que quieren darse patria, patria grande, y libertad; no en el aislamiento sino juntos, unos en las horas de peligro, unos en las esperanzas y los regocijos, unos en las tendencias hacia ulteriores y más halagüeñas realidades. Ayer los cinco pueblos de Centro América, mañana todos los del Continente hispano; porque vamos hacia la América Una, según la trayectoria espiritual de los homagnos y videntes de estas patrias nos han descrito y que sólo cierta ceguera nos impide verla. Con lo que también quisieron enseñarnos que la patria es obra de concordia, de cooperación y simpatía, que los hijos unidos hacen la patria superior con que los buenos soñaron. Con lo cual también quisieron decirnos que las guerras intestinas conspiran contra la integridad moral y territorial de la Patria y le abren la puerta a los ex- traños, que se aprovechan de nuestras debilidades y rencores; que nada es más funesto para una comunidad que las oligarquías vanidosas y ambiciosillas que convierten el gobierno en un bien privado y no en lo que debe ser, un bien público; y anteponen sus egoísmos repugnantes y sin escrúpulos a la suerte misma de la Patria. Con lo que también se indica a vuestros profesores que el risueño ideal de servicio, de ser útil a los demás, de cooperar, es la primera de las lecciones morales que ellos deben daros, jóvenes estudiantes.

Lo erigieron los mayores para advertirnos que la libertad hay que conquistarla y reconquistarla continuamente, que sólo se pierden los pueblos que se cansan de ser libres; porque si importa saber cómo fuimos libres, importa más saber cómo conservarnos libres, cómo mantener en asta firme la enseña de los libertadores: el problema que ellos resolvieron en el 56 sigue siendo nuestro problema. Para advertirnos que no basta haber heredado de nuestros abuelos la tierra que fue de ellos, sino conservar y cuidar la que será de nuestros hijos: porque los viejos supieron que uno de los ineludibles deberes del hombre y del ciudadano es la conservación, a todo trance, del suelo nativo; sin él no hay libertad económica y sin esta no hay soberanía posible. La tierra es la que sustenta a hombres libres. Los pueblos que venden sus tierras porque ya no quieren, no pueden o no saben cultivarlas con estudio y cariño, de propietarios se tornan inquilinos. Es digna de la escultura esta previsora y saludable advertencia del profeta Martí a sus pueblos de América: EL SUELO ES LA ÚNICA PROPIEDAD PLENA DEL HOMBRE Y TESORO COMÚN QUE A TODOS IGUALA, POR LO QUE PARA LA DICHA DE LA PERSONA Y LA CALMA PÚBLICA, NO SE HA DE CEDER, NI FIAR A OTRO, NI HIPOTECAR JAMÁS.

Enseña el Monumento que Centro América y la América entera, abiertas a los intereses de la civilización occidental, no se alzaron de las aguas para convertirse en factorías de los pueblos mercaderes y codiciosos, sino tierra de libertad para humanidades ansiosas de mejorar su vida y no tan solo de hacer negocios más o menos lucrativos, o de explotar nuestros recursos naturales; para gentes que vengan a construir sinceramente la patria de la nueva cultura, del hombre nuevo, que funda su prestigio y su decoro en vivir según las imperecederas normas de la justicia, la libertad, la belleza y la verdad.

Este Monumento rememora sucesos que le dan a Costa Rica, a Centro América, un sentido internacional en el Continente; que dicen cómo en días inolvi- 
dables los nuestros hablaron en su historia de pueblos pequeños y se crearon la conciencia de un cargo que cumplir en los destinos de nuestra América. Porque el buen suceso de la lucha contra el plan siniestro de Walker y de los mercaderes a él asociados, -si es que fue el de convertir a Centro América en una agencia de esclavos negros- en cierto modo desvió la iniquidad, que al extenderse, habría degradado a nuestra América, destinada por la Historia a empresas superiores de cultura. No se hizo la América para traficantes de esclavos.

Como se ve, no están desligados los sucesos históricos, que los pueblos chicos influyen a su vez en la suerte de los mayores. Sintamos, por lo mismo, la conciencia de que en estas tierras se han decidido y se decidirán acontecimientos de la Historia que tienen resonancias continentales. Así es la patria cuando se la comprende de veras, un estado de alma, de cultura, un estado de conciencia superior, conciencia de que se tiene una función y un valor, de que como hombres y como pueblos, hemos venido a este mundo a hacer algo que valga la pena. No en balde se dan patria los hombres, que se la dan para crear y crecer. Se habla de una conciencia nacional: pues bien, nada más difícil de adquirir que eso, que es mucho más que los meros instintos territoriales de un pueblo. Afortunados los países que en los fastos de sus progenitores, los nuevos hallan qué admirar e imitar. De tal admiración consciente les brota de las entrañas como un manantial de fuerzas espirituales fecundas que los hace verse más altos. En cambio, qué estéril y qué triste es la vida de los pueblos que padecen incuria, que ignoran lo que valieron sus precursores, que apenas si se dan cuenta de la indiferencia que va pagando en ellos sus ideales y entusiasmos. Se esculpieron en bronce las hazañas de los héroes, para declararnos una vez por todas que el pretérito debe conocerse y amarse, porque expresa una tradición que nos vincula con la Patria que hicieron los egregios finados de la familia. Para declararnos que hay que oír la voz de los próceres voz de la Historia, que guía a estas patrias por caminos mejores y más claros: que marchan sin brújula, y andan como a tientas, y están como perdidos, los países que no apoyan un pie en la tradición, que no consultan el testimonio autorizado de los mayores que más supieron de los negocios de sus pueblos, y los amaron, y por mejorarlos se desvelaron. El Monumento nos enseña lo que vale para una nación el espíritu previsor y vigilante de su Primer Magistrado y de cuán incalculables son los males de un pueblo que mira con indiferencia su suerte. Como también nos dice que no debemos desesperar nunca, porque en las horas tenebrosas e inciertas los pueblos tienen el gobernante oportuno que les hacía falta.

Enseña el Monumento que las leyes morales se cumplen inexorablemente y que no deben ser ultrajados los pueblos chicos por ser chicos; que también los poderosos se tambalean cuando fundan sus relaciones con los demás en el atropello y la injusticia. Y anticipándose en medio siglo a la reciente guerra europea, proclama que los pueblos pequeños, si son dignos, si no son serviles, si son ilustrados y laboriosos, también tienen derecho a ser libres como los grandes, y que si hay un coraje sagrado es el de los pueblos que se yerguen como un solo hombre en defensa de sus más caras libertades. Por eso ved, sentid vosotros, oh jóvenes, como un soplo de tempestad que agita las figuras del Monumento: Es el ademán como de fuerzas de la Naturaleza de pueblos nuevos en marcha, que aún empuñan la lanza porque todavía aletea en la sombra los genios del Mal y de la Perdición: que ya no brilla la codicia conquistadora en la punta de las bayonetas sino en el disco de las áureas monedas. Si es sumamente grave que aventureros extraños se atrevan a comprar la patria, lo sería mucho más, e ignominioso, que hijos del país de bruces se la vendieran. Conmovéos, pues, con esa resolución que se les ve a las esculturas de vencer $y$ de ser libres; se yerguen a paso de victoria, antes y hoy, y mañana también. Jóvenes estudiantes, isi lo que aguardan estos sacros bronces y los sucesos que rememoran es el cantor inspirado, que los materiales del poema inédito y las proporciones homéricas de los héroes y de las hazañas ahí están ante vuestro amor y curiosidad!

El Monumento es simbólico y en ello, su valor espiritual permanente. Dice de la actitud vigilante y defensiva contra los enemigos malos de la Patria, contra los exteriores que la amenazaron un día, y pueden amenazarla, pero también contra los internos que la amenazan a todas horas. La Costa Rica de nuestros padres expulsó del suelo materno al filibustero calculista e inescrupuloso, pero la de nuestros días tiene que sacarse del alma la concupiscencia, la codicia del oro -en muchos ciudadanos- adquirido por medios fáciles o ilícitos; la pasión del lujo, y la frivolidad -en muchas ciudadanas-; las cuantiosas deudas públicas y privadas, de lo que son secuela; la indiferencia por lo propio, la pereza, el alcoholismo, las enfermedades sociales y las discordias civiles, enemigos más terribles e implacables que los aventureros extraños: imponerse-como lo está haciendo la madre España- la disci- 
plina creadora, constructora, del trabajo, del ahorro y del estudio, hasta hacerse digna de los progenitores en aspiraciones y realizaciones.

Es simbólico el Monumento y habla de batallas que soldados de Costa Rica, a toda hora pronta al sacrificio y al servicio, dieron por la libertad y la justicia; y habla de sucesos que aleccionan a un pueblo para que empuñe la lanza cuando las empresas libertadoras y justicieras lo requieran no más; y habla también de cómo los muertos ilustres cuyas hazañas rememora no están muertos, sino que han de revivir con sus enseñanzas y ejemplos, en la conciencia de sus conciudadanos: como guías en las nuevas batallas que son las que ganemos nosotros por la nueva cultura, en su nombre y en el de la Patria. Que si en la guerra memorable Costa Rica iba a la vanguardia, en la paz vaya también, por la sensatez, por el espíritu previsor, liberal y progresista de sus hombres y mujeres dirigentes.

Es un símbolo el Monumento y en él se yerguen altivas e indignadas las patrias luchadoras de ayer, esculpidas en forma de mujeres para enseñaros, oh señoritas -tantas señoritas como aquí veo-, que vosotras sois la Patria misma, que haréis sana y fuerte en los niños venideros, y formaréis honrada y pulcra, si ese es vuestro ideal y resolución inquebrantables, si para ello en verdad os han educado. Jurad al pie del Monumento Nacional, con la conciencia clara de que sois las mantenedoras y salvadoras de la Patria, de que ésta se redime si a vosotras se redime, de que a ella se ofende si a vosotras se ofende, de que la envilecen los que os envilezcan: jurad que de vuestros regazos saldrá la Patria nueva, sencilla, sin ostentaciones, estudiosa, laboriosa y previsora, preocupada cordialmente de sus sementeras y de sus niños. Que al fin de cuentas, jóvenes estudiantes, al corazón, a las entrañas mismas de la Patria con las mujeres se llega, y sin ellas al trastorno, la disolución y la muerte.

J. García Monge

Repertorio Americano, 19 de septiembre de 1921, pp. 29-31.

\section{NOTAS}

1 Según Mr. Soulé, agente de Walker en Nueva Orleans, el bucanero yanque se proponía consolidar en una República anglosajona las cinco de Centroamérica y con capitalistas norteamericanos dominar la ruta interoceánica de Nicaragua, cosa que, en parte, a estas horas ya se ha logrado. 